\title{
Cerebral infarction due to intracranial sinus thrombosis
}

\author{
M. ATA \\ From Lewisham Group Laboratory, Lewisham Hospital, London
}

SYNOPSIS Four cases, two infants and two adults, of extensive thrombosis of the intracranial venous sinuses are described. Infarction of the brain had occurred in three cases. The first two cases presented as diabetic coma. The third case has been included to represent primary puerperal cerebral venous thrombosis. Extensive venous sinus thrombosis was seen at post-mortem examination in the fourth case, an infant who died suddenly, but there was no cerebral infarction in this case.

Although thrombosis of a cerebral venous sinus is not uncommon, extensive occlusion of the venous drainage of the brain seldom occurs. Primary or non-infective thrombosis of a vein or a sinus may occur in a number of systemic disorders, viz., cachexia, marasmus, heart disease, carcinoma, high fevers, blood dyscrasias, and post-operative and post-traumatic states (Kendall, 1948; Barnett and Hyland, 1953; Bayard, 1960). A primary cerebral thrombosis in the puerperium has been extensively discussed (Symonds, 1940; Martin and Sheehan, 1941; Stansfield, 1942; Hyland, 1950; J. Okla. med. Ass., 1960).

Diabetes mellitus does not appear to have been recorded before as a precipitating factor in the causation of cerebral venous sinus thrombosis. Two of the four cases described in this paper presented as diabetic coma with ketosis. The coma persisted in spite of control of the ketosis and extensive venous sinus thrombosis with cerebral infarction was found at necropsy.

\section{CASE REPORTS}

CASE 1 Mrs. D. C., aged 47, complained of excessive thirst, polyuria, and debility for a year. On 1 August 1962 she developed a boil on the nape of her neck which did not respond to oral penicillin. On the night of 4 August she complained of headache and dizziness, she was very irritable, had slurred speech, and began to vomit. She lost conciousness and was admitted to hospital on the morning of 5 August. Her blood sugar was $450 \mathrm{mg} . / 100 \mathrm{ml}$., Na $136 \mathrm{mEq} . / 1$., K $2.3 \mathrm{mEq} . / 1$., Cl. $101 \mathrm{mEq} . / 1$, and alkali reserve $5.7 \mathrm{mEq} . / 1$. Despite treatment with intravenous insulin and fluids, she made no clinical improvement, although the electrolyte and blood sugar levels had improved towards the evening of the day of admission. Later, at 8.45 p.m., cardiac arrest Received for publication 30 December 1964. occurred; this was treated with an electric cardiac pacemaker. One hour later cardiac arrest recurred and respiration became irregular. External cardiac massage, tracheal intubation, and intermittent positive pressure respiration was carried out and she was transferred to the resuscitation unit. In a short time her pulse became strong and regular. On 6 August her blood sugar was $324 \mathrm{mg} . / 100 \mathrm{ml}$., Na $148 \mathrm{mEq} . / 1$., K $2.1 \mathrm{mEq} . / 1$., Cl. $101 \mathrm{mEq} . / 1$., and alkali reserve $28 \mathrm{mEq} . / 1$. She remained unconscious and on 8 August hypotension developed and her arms and legs started twitching. Tendon and superficial reflexes had been absent from the first day of admission but the pupils, which were initially constricted and responded to light, became dilated and failed to respond to light. No papilloedema was seen. She had a fast atrial fibrillation. Terminally on 10 August her blood sugar levels were as high as $1,160 \mathrm{mg} . / 100 \mathrm{ml}$., and $1,728 \mathrm{mg} . / 100 \mathrm{ml}$., and blood urea was $130 \mathrm{mg} . /$ $100 \mathrm{ml}$.

Necropsy was carried out two days after death. Pus, from which Staph. aureus phage type 747 was

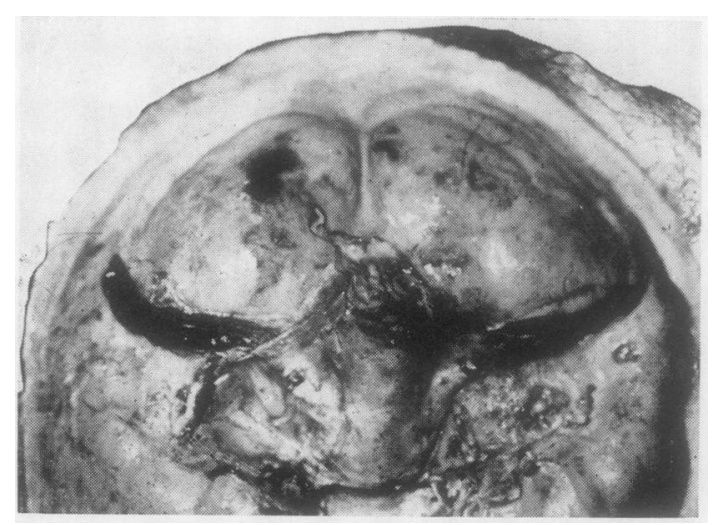

FIG. 1. Photograph showing thrombi in the lateral sinuses of case 1 . 


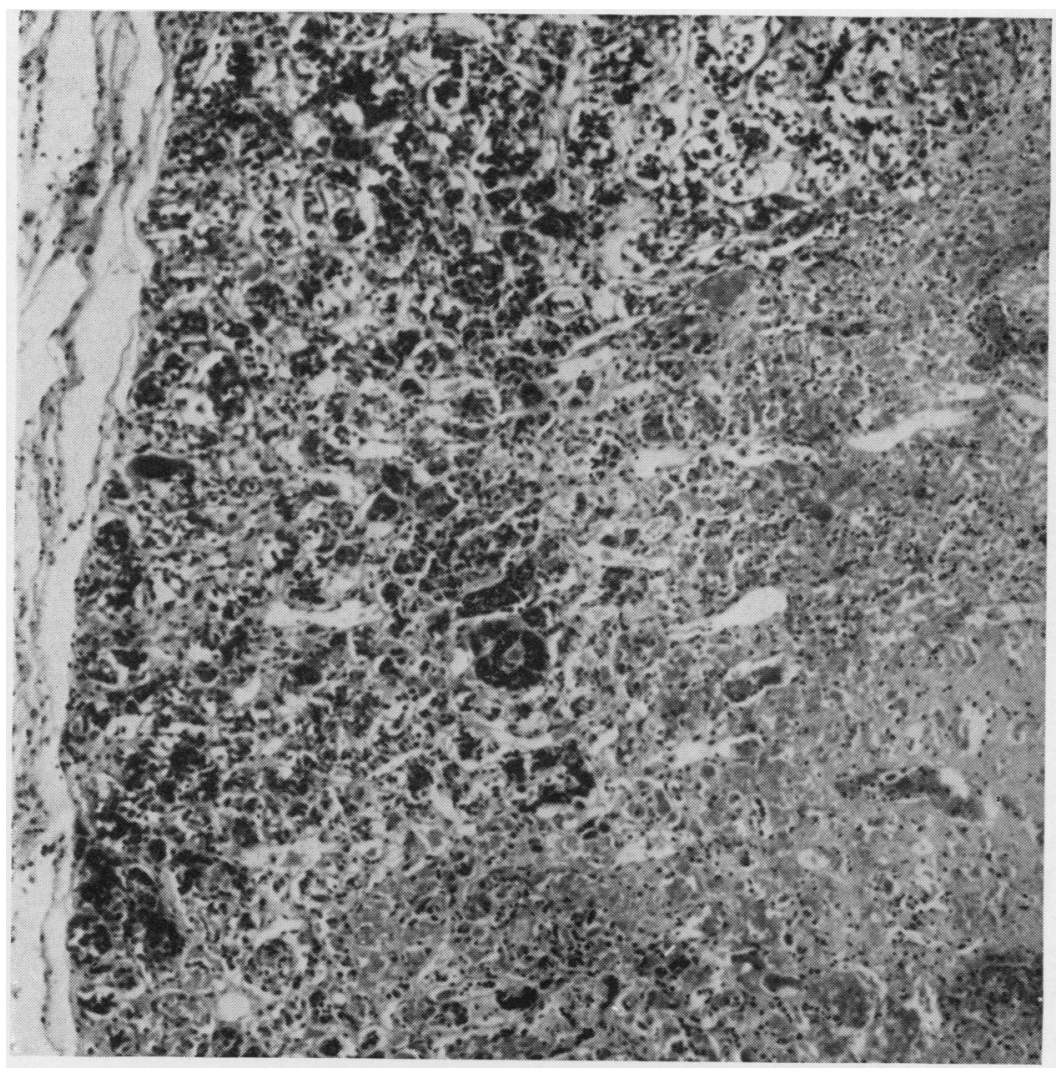

FIG. 2. Low-power

photomicrograph of the infarcted pituitary of case 1 , with surviving cells in the peripheral zone Haematoxylin and eosin $\times 75$.

grown, was located in the deep subcutaneous tissue in the nape of the neck, but there was no discharging sinus. Apart from slight pericardial bruising no abnormality of the thoraco-abdominal viscera could be found. Both the lateral sinuses contained dark brown ante-mortem thrombi (Fig. 1) and the cerebral veins were distended. On the right side the thrombus extended through the jugular foramen into the internal jugular vein. There were diffuse petechial haemorrhages in the cerebral hemispheres, cerebellum, and the brain-stem. The medulla oblongata, pons, and cerebellum were extremely friable, softened, and necrotic. The basilar artery as well as the other cerebral arteries were patent. Microscopically the cerebrum showed small haemorrhages, venous distension, and areas of necrosis. The cerebellum and brain-stem showed severe extensive infarction. The pituitary, with the exception of a few cells in the periphery, was completely necrotic (Fig. 2). It was haemorrhagic and infiltrated by polymorphonuclear leucocytes. The vessels were markedly engorged. The pancreas showed sparse islets of Langerhans and these were mostly hyalinized.

CASE 2 A well-nourished baby girl (F. W.), aged 8 months, was admitted to hospital in a state of semicoma on 25 March 1958. She had been unwell for two days previously and had vomited occasionally. She had a temperature of $101^{\circ} \mathrm{F}$. and a regular pulse of $200 / \mathrm{min}$. Her blood sugar level was $1,020 \mathrm{mg} . / 100 \mathrm{ml}$. The diabetes was effectively controlled with intravenous insulin and fluid within 12 hours of admission but the coma deepened and the right side of her body started to twitch. All the reflexes except the pupillary light reflex were absent. On 28 March a lumbar puncture showed that the cerebrospinal fluid was clear but under increased pressure, cells less than $2 / \mathrm{c} . \mathrm{mm}$., protein $10 \mathrm{mg} . / 100 \mathrm{ml}$. She retained only an occasional milk feed and was never fully conscious. On 6 April her temperature rose to $104^{\circ} \mathrm{F}$. The left arm, as well as the right side, showed Jacksonian movements, and she made frequent encephalopathic cries. Optic discs appeared full but no definite papilloedema was seen. There was no neck rigidity. The liver was palpable two fingers below the costal margin. There was no evidence of chest infection. In addition to the original antibiotic cover of streptomycin and penicillin, terramycin was administered to treat a suspected cerebral abscess. Despite an effective control of blood sugar and electrolytes she remained comatose until she died on 10 April.

Necropsy was performed three days after death. The lungs were well aerated and there was no evidence of a respiratory infection. All the visceral organs except those of the central nervous system were normal, and there was no evidence of septicaemia. In the cranial 


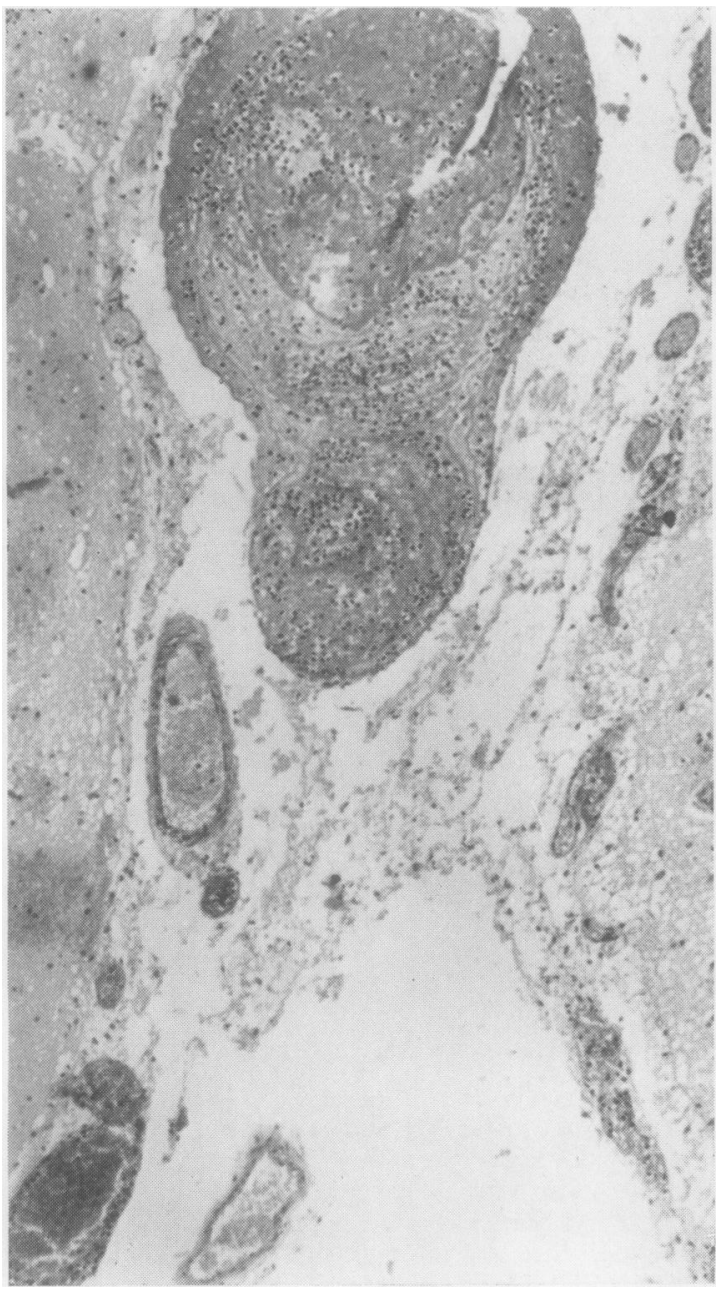

FIG. 3. Low-power photomicrograph of a dural sinus and the infarcted brain of case 2. Haematoxylin and eosin $\times 40$.

cavity there was thrombosis of the superior and inferior sagittal and the straight sinuses. The great vein of Galen and the superior meningeal and cerebral veins on both sides contained ante-mortem thrombi. The basal venous sinuses showed no thrombosis. There was massive haemorrhagic infarction of the whole of the right cerebral hemisphere and also of the parasagittal part of the left cerebral cortex. The middle ears were normal. Microscopically the infarct was haemorrhagic with marked venous congestion and thrombosis of veins and sinuses (Fig. 3). This was regarded as primary venous thrombosis.

CASE 3 A girl of 15 (L. L.), 39 weeks pregnant, was delivered, with the help of forceps, on 28 November 1963 of a male infant weighing $5 \mathrm{lb} .4 \mathrm{oz}$. Towards term she had mild toxaemia. She was well for five days after delivery but then became irritable and refused to feed her child. She was lethargic and gradually became comatose. On 4 December she showed signs of a rightsided hemiplegia; she had generalized hypertonicity and responded only slightly to painful stimuli. Lumbar puncture showed that pressure of cerebrospinal fluid was $300 \mathrm{~mm}$. water, cells $260 / \mathrm{c} . \mathrm{mm}$. (lymphocytes $12 \%$, polymorphs $88 \%$ ), protein $160 \mathrm{mg} . / 100 \mathrm{ml}$, globulin ++ , chloride $720 \mathrm{mg} . / 100 \mathrm{ml}$, sugar $45 \mathrm{mg} . / 100 \mathrm{ml}$. No organisms were seen in the sediment and none were cultured. Skull and chest radiographs were normal and $c$ there was no clinical evidence of septicaemia. Next day, $\vec{O}$ the right side of her body started to twitch. A second lumbar puncture was unsuccessful and only a little carebrospinal fluid, heavily contaminated with blood, was obtained. She was transferred to the Atkinson Morley Hospital on 5 December. A ventriculogram and an E.E.G. confirmed that the lesion was localized in the $\infty$ left frontoparietal region and was suspected to be an infarct, possibly resulting from primary puerperal intracranial thrombosis. She died on 7 December.

Necropsy was carried out two days after death. No abnormality was found except in the central nervous system. The genito-urinary system and pelvis showed no $\mathbb{D}$ evidence of any infection or thrombosis. The uterus was vascular and enlarged, but normal for early in the puerperium. The endocrine system was normal. The pituitary was unfortunately not preserved. The superior sagittal sinus contained an adherent thrombus which $\vec{\varphi}$ extended into the dominant left lateral sinus and left $\mathscr{S}$ internal jugular vein. The right lateral sinus was small and did not contain any thrombus. Some of the superficial cerebral veins draining into the superior sagittal sinus were also thrombosed. There was haemorrhagic infarction involving the parasagittal region of both the cerebral hemispheres but mainly the parietal and occipital regions of the left hemisphere (Fig. 4). There was also slight leakage of blood into the subarachnoid space. Histological examination showed venous infarction of the brain and thrombosis of the superficial veins and dural sinuses.

CASE 4 A baby girl (W. S.), aged 9 days, was admitted to hospital on 14 April 1963 with diarrhoea. No bacterial or viral pathogens were isolated from the faeces, and the diarrhoea was regarded to be of dietary origin. The infant $\delta$ was discharged after a stay of 20 days in hospital during which time she gained $2 \mathrm{lb}$. and then weighed $8 \mathrm{lb}$. A 을 week after discharge from the hospital, the infant started vomiting and collapsed. She died a few hours later.

At necropsy the body of the infant appeared dehydrated with sunken eyes and fontanelles. Total weight was $\mathrm{N}$ $6 \mathrm{lb} .12 \mathrm{oz}$. A culture from gastro-intestinal contents yielded $B$. coli 0111 . No abnormality of any significance was found except in the central nervous system where $\omega$ extensive thrombosis of the dural sinuses and the cortical $\sigma$ veins was present. The cerebral cortex appeared intensely congested, but there was no infarction or necrosis microscopically.

\section{DISCUSSION}

Although several small emissary veins join the $\frac{\mathcal{Q}}{\Phi}$ intracranial venous sinuses and the extracranial 


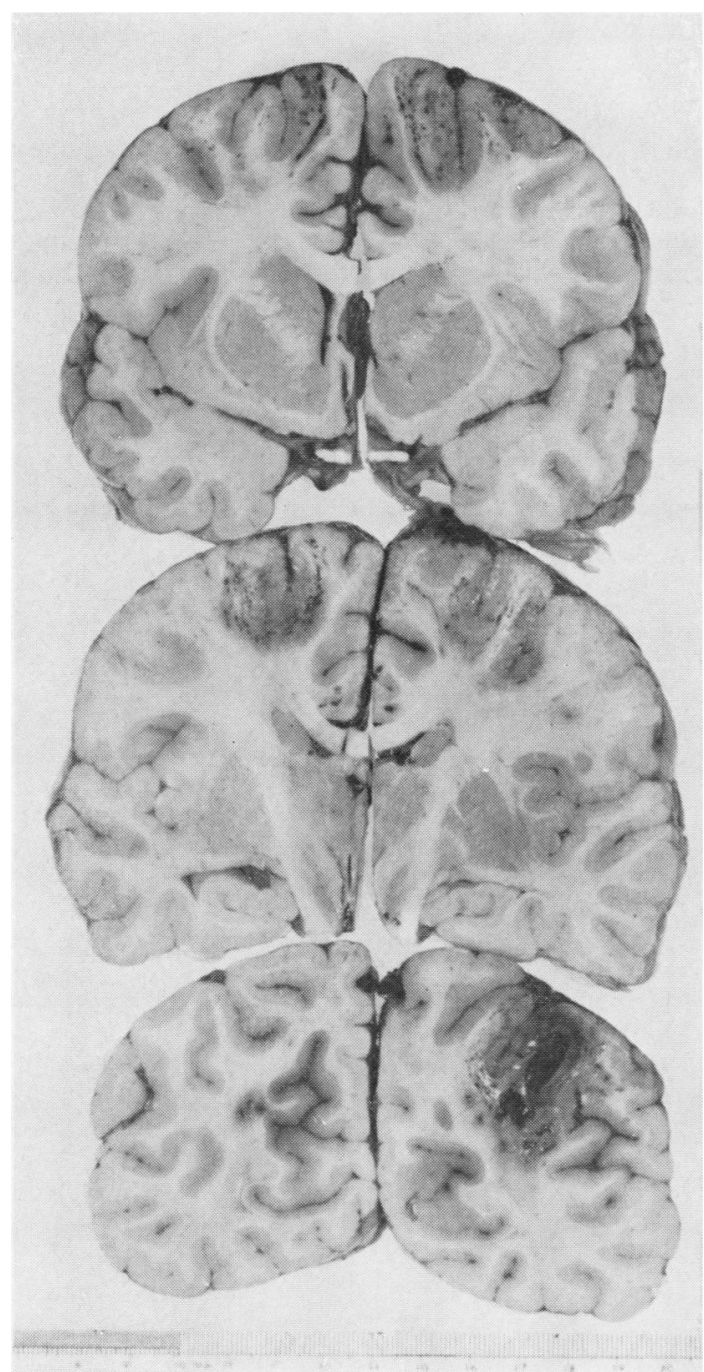

FIG. 4. Photograph of the slices of brain of case 3, showing bilateral parasagittal haemorrhagic infarctions.

venous plexi, the main venous drainage of the brain depends on the patency of the lateral venous sinuses and the internal jugular veins. Occlusion of one lateral sinus is insufficient to cause severe venous obstruction (Symonds, 1956) unless there is a congenital absence of the opposite sinus. Wocdhall (1936) found that $4 \%$ of normal people had one lateral sinus only.

Cerebral infarction may occur if the venous occlusion is extensive. Infarction of this type is characterized by multiple diffuse punctate haemorrhages, venous engorgement, hydropic degeneration of neurones, and cyst formation. Thus it differs from the softening that occurs in the commoner arterial occlusion. Thrombosis of a venous sinus may not result in infarction as there is a rich venous anastomosis on the surface of the brain, or the infarct may be very small. Rarely death occurs, as in case 4, without infarction due to extensive cerebral venous occlusion (Greenfield, Blackwood, McMenemey, Meyer, and Norman, 1958).

Cases 1 and 2 as first presented appeared to be of simple diabetic coma, but soon the problem of diagnosis became apparent when coma persisted despite correction of metabolic errors. It would appear that venous sinus thrombosis was present from the beginning of the comatose state. Cardiac and respiratory disturbances in case 1 may have been due to punctate haemorrhages in the floor of the fourth ventricule.

Several factors may predispose to intracranial venous sinus thrombosis. These include severe dehydration due to polyuria and vomiting, profound hypotension and infection, all of which commonly occur in diabetes mellitus. Case 2 illustrates that infection is not essential.

Necrosis of the pituitary in case 1 is an interesting finding. Plaut (1952) found subtotal necrosis of the anterior pituitary on 13 occasions in 147 routine necropsies. He believed that this occurred as an exaggeration of a normal process in the last few days of life. Sheehan $(1937,1948)$, however, from his puerperal necropsy studies maintains that there exists a close relationship between the severity of the circulatory collapse and the extent of the pituitary necrosis. Sheehan and Stanfield (1961) believe that the causative factor of the puerperal pituitary necrosis is the arterial spasm. Daniel, Prichard, and Treip (1959), however, consider that there is no direct arterial supply to the parenchyma of the anterior pituitary. Pituitary necrosis has been described in a case of bilateral infective cavernous sinus thrombosis (Weisman, 1944). Professor P. M. Daniel made a histological examination of the pituitary of the present case. He considers that the pituitary necrosis could not be explained by the interference in the venous drainage and that it had probably resulted from hypotension. Sheehan and Stanfield (1961) regarded any thrombosis in the pituitary veins as secondary to the necrosis and haemostasis. Neverthless, diabetes may be responsible for the pituitary infarction in this woman, as similar infarcts are occasionally seen in cases of diabetes mellitus. No one knows the cause of pituitary necrosis in diabetes mellitus, but Brennan, Malone, and Weaver (1956), Plaut (1952), and Pinkerton and Adams (1961) have described several cases.

Clinically intracranial venous sinus thrombosis 
may be a diagnostic problem. Headache, drowsiness, focal or generalized convulsive seizures, slowly progressive or even transient unilateral or bilateral focal signs may develop. These symptoms and signs have a slower onset as compared with arterial lesions and in this respect resemble infective processes. Occasionally, however, the course may be rapid as in case 4 and death may occur without any focal cerebral lesions. Although the cerebrospinal fluid is generally under increased pressure, as in cases 2 and 3, papilloedema is only occasionally observed. The cerebrospinal fluid is usually clear but may be stained by blood leaking from the infarct or the engorged veins. Cells may be increased but no micro-organisms are found and the levels of sugar and chloride are normal although that of protein may be slightly raised.

Frenckner (1937) described a technique of direct sinography which may localize the sinus thrombosis but it requires drilling a hole in the cranial vault and is not without danger. Carotid angiography is now usually employed in localizing sinus thrombosis. Electroencephalography and ventriculography may be helpful in localizing an affected area.

The treatment is no less a problem than the diagnosis. The haemorrhagic nature of the infarction, especially in the puerperium, is a contraindication to anticoagulant therapy, but local infusion of a thrombolytic agent may prove $\stackrel{\frac{\mathrm{O}}{2}}{\mathrm{~F}}$ useful.

My thanks are due to Dr. J. H. Mosley, Dr. J. M. S. Knott, and Miss L. E. Hurter for permission to publish their cases, to Dr. R. D. Clay and Dr. M. R. Crompton for some of the post-mortem material, and to Dr. J. R. Tighe and Dr. D. N. Whitmore for their helpful $\varrho$ criticism. Finally I wish to thank Professor P. M. Daniel कै for his opinion on the pituitary.

\section{REFERENCES}

Barnett, H. J. M., and Hyland, H. H. (1953). Brain, 76, 36. Bayard, C. (1960). Confin. neurol. (Basel), 20, 452.

Brennan, C. F., Malone, R. G. S., and Weaver, J. A. (1956). Lancet, 2, 12.

Daniel, P. M., Prichard, M. M. L., and Treip, C. S. (1959). Ibid., 2, 927.

Frenckner, P. (1937). Proc. roy. Soc. Med., 30, 413.

Greenfield, J. G., Blackwood, W., McMenemey, W. H., Meyer, A., and Norman, R. M. (1958). Neuropathology, p. 92. Arnold, 응 London.

Hyland, H. H. (1950). J. Amer. med. Ass., 142, 707.

J. Okla. med. Ass. (1960). 53, 824.

Kendall, D. (1948). Brain, 71, 386.

Martin, J. P., and Sheehan, H. L. (1941). Brit. med. J., 1, 349.

Pinkerton, P. H., and Adams, J. H. (1961). Scot. med. J., 6, 156.

Plaut, A. (1952). Amer. J. Path., 28, 883.

Sheehan, H. L. (1937). J. Path. Bact., 45, 189.

- (1948). Irish J. med. Sci., 241.

—, and Stanfield, J. P. (1961). Acta endocr. (Kbh.), 37, 479

Stansfield, F. R. (1942). Brit. med. J., 1, 436.

Symonds, C. P. (1940). Brit. med. J., 2, 348.

Symonds, C. P. (1956). Neurology (Minneap.), 6, 681.

Weisman, A. D. (1944). New Engl. J. Med., 231, 118.

Woodhall, B. (1936). Arch. Surg., 33, 297. 